\title{
Understanding academic performance of international students: the role of ethnicity, academic and social integration
}

\author{
Bart Rienties • Simon Beausaert • Therese Grohnert • \\ Susan Niemantsverdriet • Piet Kommers
}

Published online: 24 July 2011

(C) The Author(s) 2011. This article is published with open access at Springerlink.com

\begin{abstract}
More than 3 million students study outside their home country, primarily at a Western university. A common belief among educators is that international students are insufficiently adjusted to higher education in their host country, both academically and socially. Furthermore, several groups of international students experience considerable amounts of stress while adapting to the culture of the host-institute. Several researchers argue that studies on adaptation of international students should widen its focus to the underlying mechanisms that leads towards this "misalignment". In a cross-institutional comparison among 958 students at five business schools in the Netherlands, differences in academic performance between local and international students were identified by focussing on their levels of academic and social integration. Students' academic integration was measured with the Students' Adaptation to College Questionnaire (SACQ), while students' social integration was measured with a newly developed and validated
\end{abstract}

\footnotetext{
B. Rienties $(\square)$

Centre for Educational and Academic Development, University of Surrey, Guildford, England, UK e-mail: b.rienties@surrey.ac.uk
}

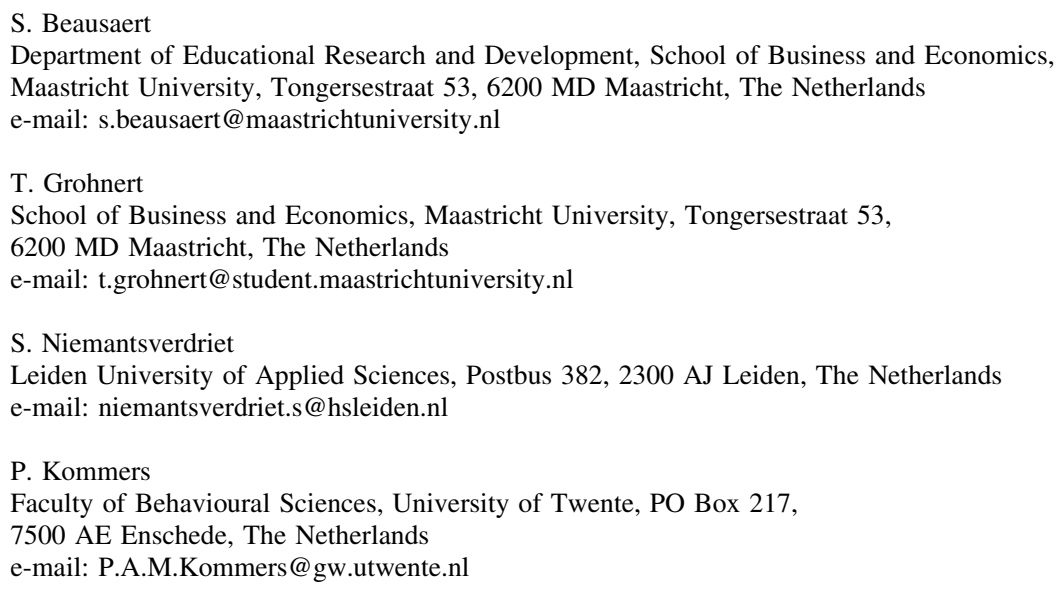


questionnaire. The results indicate that the degree of academic success of international students is multi-faceted. International students with a (mixed) western ethnic background perform well on both academic and social integration, and also attained higher studyperformance in comparison to domestic students. In contrast, international students with a non-Western background are less integrated compared to other international students. Nevertheless, they have a similar study-performance. Finally, academic adjustment is the main predictor of study-performance for Dutch, Western and Mixed-Western students. Social adjustment was negatively related to study-performance. The lack of fit for predicting long-term study success of non-Western students indicates that their academic and social integration processes are more complex and non-linear.

Keywords International students · Academic integration - Social integration · Academic performance $\cdot$ Ethnicity

\section{Introduction}

An increasing number of students prefer to study at a university abroad (Healey 2008; Russell et al. 2010). In 2007, 3 million students studied abroad, which is almost three times higher compared to the figures of 1990 (OECD 2009). Until recently, Anglo-Saxon countries like the US, UK or Australia primarily attracted large numbers of foreign, international, students. More recently, also non-English speaking countries are increasingly attracting foreign students. In comparison to the UK (14\%) or Australia (20\%), the degree of internationalisation in higher education in the Netherlands is relatively low. Only 5\% of the student population that attended higher education in 2000-2007 were international students (Dutch Ministery of Education 2010; OECD 2009). However, enrolments of international students are significantly higher in international business education programmes in the Netherlands, whereas in some business schools international students even outnumber local students (Rienties et al. 2011). By focusing on the front-runners of internationalisation in the Netherlands in this article, we are convinced that important lessons-learned from these business schools can be identified for higher educational institutes that attract international students.

Beyond the attraction of an enriched, international atmosphere at Dutch universities (Eringa and Huei-Ling 2009; Van der Wende 2003), there is some doubt about the academic and social integration of international students. A common assumption in higher education is that academic integration, that is the extent to which students adapt to the academic way-of-life (Tinto 1975), of international students is not well-aligned with the requirements of higher educational institutes (Asmar 2005; Barrie 2007; Jochems et al. 1996; Morrison et al. 2005; Russell et al. 2010). Recent research has found a mixed picture on whether international students underperform in academic integration and academic performance. Therefore, Morrison et al. (2005) claim that research should widen its focus from comparing international-versus domestic students' performances to finding out the underlying mechanisms of academic and social integration. We define social integration as the extent to which students adapt to the social way-of-life at university.

The prime goal of this paper is to characterise the typical differences in academic- and social integration between domestic and international students in five business schools in the Netherlands. In contrast to most studies on cross-cultural transition and adaptation of international students, who primarily use rather simplistic statistical methods such as t-test comparisons and correlation analyses, in this study we will use hierarchical regressions in 
order to understand the impact of academic and social integration on student retention. That is, we assess whether differences in academic and social integration between domestic and international students actually have an impact on academic performance, as measured by grade point average scores (GPA) and European Credit Transfer and Accumulation System points obtained (ETCS) after their first year of study.

\section{Academic and social integration}

A large number of studies have addressed student retention or persistence in higher education. The interaction student attrition model of Tinto $(1975,1998)$ considers that students have a variety of educational experiences, competences and skills, values as well as family and community backgrounds before they enter into higher education. As a result, both individual and social attributes will influence the student's integration into higher education. According to Tinto $(1975,1998)$, students not only need to persist in their study in order to graduate (i.e. academic integration), but they also need to participate in the student culture, both within and outside the immediate context of the learning environment (i.e. social integration).

Severiens and Wolff (2008) found that students who feel at home, who are well connected to fellow-students and teachers and who take part in extra-curricular activities are more likely to graduate. Also Wilcox et al. (2005) found that social support by family and friends (i.e. social networks of students) has a positive influence on the study-success of first-year students. Having friends, sharing accommodation with other students as well as (informal) contacts with the university staff positively influences social integration. Although Tinto's constructs have been validated by empirical research, when applying the constructs to multiple institutes or institutional programmes support varied (Mannan 2007; Zepke and Leach 2005). For example, by comparing students in five study programmes in junior and senior years, Mannan (2007) found that students from different subjects had different levels of academic and social integration.

In line with Tinto's interaction model, Baker and Siryk (1999) detected academic and social integration to be influential on study performance. Baker and Siryk (1999) distinguish four concepts in academic integration: academic-, social-, personal- \& emotional adjustment and attachment. Academic adjustment refers to the degree of a student's success in coping with various educational demands such as motivation, application, performance and satisfaction with the academic environment. Social adjustment describes how well students deal with the interpersonal-societal demands of a study, such as making friends, being part of social activities or being able to work in groups. The personal and emotional adjustment scale indicates the level of psychological and physical distress while adapting to the local academic way-of-life. Finally, attachment reflects the degree of commitment to the educational-institutional goals. In a large number of studies in US colleges, the four concepts of academic adjustment are positively related with study progress and study performance (Baker and Siryk 1999).

Potential obstacles for social integration of international students

Current research indicates that institutes and the social networks of students have a large influence on how first-year students adjust (Christie et al. 2004; Severiens and Wolff 2008; Tinto 1998; Wilcox et al. 2005; Zepke and Leach 2005). In the context of international students, additional factors might play a role for successful adaptation, acculturation, academic and social integration (Russell et al. 2010; Sam and Berry 2006; Ward et al. 
2004; Zhou et al. 2008). For an (historical) overview of theoretical models of acculturation and adaptation in international students in higher education, see Ward et al. (1998) and Zhou et al. (2008). Berry (1999, p. 40) describes the transitional challenges of students from two different cultures as acculturation, which, in a broader sense was defined as "the process of cultural change that results when two (or more) cultural groups come into contact with each other; the changes occur in both groups, but usually one (the dominant group) changes less than the other(s)". When international students and domestic students work and learn together, both need to adapt in order to work together effectively (Russell et al. 2010).

In a recent study conducted among approximately 900 international students in Australia, Russell et al. (2010) found that $41 \%$ of international students experience substantial levels of stress, which are often a result of homesickness, cultural shocks, or perceived discrimination. In comparison to domestic students, international students need to pay additional attention and effort to social integration, as their family, friends from their home country and social network are mostly not within easy reach (Bochner et al. 1977; Zhou et al. 2008). Furthermore, the social network of international students is less likely to be fully aware of the explicit and implicit customs or culture of the host institute/country, in particular when non-western students attend higher education at a western institute (Asmar 2005; Bochner et al. 1977; Rienties et al. 2011; Russell et al. 2010; Zhou et al. 2008). Therefore, based upon an extensive literature review on the concepts of student retention (Baker and Siryk 1999; Beyers and Goossens 2002) and acculturation and adaptation (Berry 1999; Sam and Berry 2006; Ward and Rana-Deuba 1999; Zhou et al. 2008), we have extended the model of Tinto with five additional social integration factors that are specifically relevant for international students, namely: perception of the faculty by the social network of students; social support by family and friends; social life; ethnic background, and financial support.

The perception of faculty, that is the perceived esteem or reputation of the faculty/ institute by family, friends, the general public and future employers, influences the social integration of students (Gloria et al. 2005; Thomas 2002). For example, Ozga and Sukhnandan (1998) found that non-completing students had a lower compatibility with the institute, which was in part caused by less compatible social networks. Higher educational institutes are increasingly aware of impacts of international ranking lists such as those published in the Financial Times on the choices that international students make when selecting an educational programme. Furthermore, appropriate academic support structures and institutional facilities have been found to enhance learning outcomes of students (Russell et al. 2010; Zhou et al. 2008). Therefore, higher educational institutes spend considerable effort in providing (non-) academic facilities to students (e.g. academic study support, campus, ICT-facilities, social life, cultural programmes) in order to differentiate themselves from other institutes (Bok 2003; Thomas 2002). Therefore, we expect that a well-perceived reputation of an institute for higher education by the social network of the student is expected to have a positive influence on academic performance.

Secondly, Wilcox et al. (2005) found out that study-and social support by family and friends are influential on first-year students' study-success. In general, the role of the family on the attitudes and motivation of students has been consistently found in educational psychology (e.g. Attewell et al. 2006; Cokley et al. 2001; Ozga and Sukhnandan 1998). Students who drop out of higher education often state that their social networks provided insufficient support in order to continue (Bochner et al. 1977; Christie et al. 2004; Meeuwisse et al. 2010; Ozga and Sukhnandan 1998). Therefore, we expect that study- and 
social support by family and friends will have a positive influence on academic performance.

Thirdly, the social life outside the academic environment has a strong influence on academic integration. Having a sufficient number of friends from the same culture as well as host-culture (Bochner et al. 1977; Furnham and Alibhai 1985), sharing accommodation with other students (Ward et al. 1998), being member of a study association, student fraternity or joining a sports club can influence social integration and finally increase academic performance (Bok 2003; Ozga and Sukhnandan 1998; Russell et al. 2010; Severiens and Wolff 2008). This allows students to establish a social life that is closely attached to the university setting (Tinto 1998). International students who experience considerable levels of stress seem to be less connected to the academic and social life at university (Russell et al. 2010; Ward et al. 2004).

Fourthly, research on factors for drop-out and retention indicates that financial constraints can have significant impact on study progress (Thomas 2002). For example, $45 \%$ of the cohort investigated by Thomas (2002) indicated to have substantial financial concerns. Meeuwisse et al. (2010) found that drop-out students from low socio-economic backgrounds were more affected by problems in their home or personal situation, which is directly related to their financial situation and financial support by their social network. Finally, international students who perceive stress at the host institute are often also worried by their financial situation (Russell et al. 2010).

Finally, research on cross-cultural differences has highlighted that both national and ethnic identity (Asmar 2005; Bochner et al. 1977; Eringa and Huei-Ling 2009; Phinney 1990; Yazedjian and Toews 2006) influence how students learn in social networks. Most research on international students use a single variable for measuring ethnic identity of students, primarily nationality (e.g. Morrison et al. 2005; Russell et al. 2010; Ward and Kennedy 1993). However, an extensive bulk of research has identified that the nationality and ethnicity of the parents have a strong influence on the cognitive and social development and the ethnic identity of students (Gloria et al. 2005; Meeuwisse et al. 2010). Given the increased mobility and internationalisation of the workforce in Europe, an increasing number of students is raised by parents with different (multi-)cultural backgrounds. If researchers take into consideration the ethnic background of parents, mostly this is done by questioning the nationality of the parents. However, this might lead to a misalignment of the ethnic identity of a student. For example, a third-generation Turkish family living in the Germany with German citizenship may speak only Turkish at home. This student will be labelled as German in studies taking only nationality into consideration, while he/she probably feels German and Turkish at the same time, which is referred to as a mixed ethnic identity or "mixed-western identity".

\section{Research questions}

Based upon the eight academic and social integration factors identified above, the following research questions are addressed in order to assess whether international students' academic and social integration differs from domestic students and whether these differences have an influence on academic performance:

- To what extent do international students differ from domestic students with respect to academic and social integration?

- To what extent do differences in academic and social integration between domestic and international students have an impact on academic performance? 


\section{Methods}

Setting and participants

In this research, academic and social integration will be compared among domestic Dutch and international students using a dataset that was composed from five business schools that offer business programmes to first-year bachelor students in the Netherlands. This dataset was constructed as part of a wider national project called "Acculturation", which aims to identify and solve potential obstacles in adapting to Dutch higher educational institutes. Most business schools that participated in this research have extensive experience of providing a rich learning experience to international students. Furthermore, all five business schools offer extensive introduction programmes for (international) students. They also have academic support structures (i.e. coaching, buddies) and they use active or small-class size learning methods such as Problem-Based Learning or competency-based education. The integrated questionnaire was distributed in class among 1,887 first-year full-time bachelor students after 6-8 months of study. After removing incompletely filled in questionnaires, the answers of 958 out of 1,887 students were included in the dataset of this study; a response rate of $50.8 \%$. A possible explanation why only half of the respondents completed the questionnaire may be due to the fact that not all participants were present when the questionnaire was distributed during class. $52 \%$ of the respondents were male and $29 \%$ of the respondents had a Dutch citizenship. Respondents were assured that their individual responses and particular institutions would not be identified in any published account of the results.

Measurements

\section{Student adaptation to college questionnaire}

Based upon the student persistence model of Tinto (1975), students' academic integration was measured by the Student Adaptation to College Questionnaire (Baker and Siryk 1999), which consists of 62 items and is divided into four scales, namely: academic adjustment; social adjustment; personal-emotional adjustment; and attachment. This questionnaire has been validated by various studies (for overview, see Baker and Siryk 1999). Furthermore, applications of the SACQ confirmed that the questionnaire is applicable to a European context (Beyers and Goossens 2002).

\section{Social integration questionnaire}

Students' social integration was measured by our own developed questionnaire based upon a literature review (SIQ; Rienties et al. 2011), which consists of 15 items, divided into four constructs, namely: perception of the faculty; study support; student's satisfaction with social life; and financial support. Example questions of the eight scales, the number of items per scale and respective Cronbach's alphas are illustrated in Table 1.

The four scales of the social integration questionnaire were validated in two steps. First, an exploratory factor analysis (principal component analysis) with direct oblimin rotation, conducted on the data collected at Institute A $(n=526)$, immediately indicated the existence of four factors, with item loads of .45 and more. The first component had an eigenvalue of 3.81 (corresponding to $25 \%$ of the explained variance), the second 
Table 1 Measures: Questionnaires, Item examples, Cronbach's alphas and descriptive statistics

\begin{tabular}{|c|c|c|c|c|c|c|}
\hline Scale & $\begin{array}{l}\mathrm{N} \\
\text { items }\end{array}$ & Exemplary item & SUM & M & SD & $\alpha$ \\
\hline \multicolumn{7}{|c|}{ Student adaptation to college questionnaire (Baker and Siryk 1999) } \\
\hline Academic adjustment & 24 & $\begin{array}{l}\text { I know why I am at this institute } \\
\text { and what I want out of it }\end{array}$ & 143.98 & 3.33 & 0.48 & .83 \\
\hline Social adjustment & 20 & $\begin{array}{l}\text { I am meeting as many people } \\
\text { and making as many friends as } \\
\text { I would like at the institute }\end{array}$ & 124.49 & 3.46 & 0.55 & .84 \\
\hline $\begin{array}{l}\text { Personal-emotional } \\
\text { adjustment }\end{array}$ & 15 & $\begin{array}{l}\text { I have been feeling tense and } \\
\text { nervous lately }\end{array}$ & 91.19 & 3.38 & 0.68 & .84 \\
\hline Attachment & 15 & $\begin{array}{l}\text { I expect to stay at this university } \\
\text { for my master degree }\end{array}$ & 104.53 & 3.87 & 0.59 & .85 \\
\hline \multicolumn{7}{|c|}{ Student social integration questionnaire (Rienties et al. 2011) } \\
\hline Perception faculty & 3 & $\begin{array}{l}\text { I think that my acquaintances/ } \\
\text { friends have a good perception/ } \\
\text { image of the faculty }\end{array}$ & 11.39 & 3.80 & 0.71 & .76 \\
\hline Study support & 3 & $\begin{array}{l}\text { My family encourages me to stay } \\
\text { in the faculty }\end{array}$ & 12.07 & 4.02 & 0.80 & .87 \\
\hline $\begin{array}{l}\text { Student's satisfaction } \\
\text { with social life }\end{array}$ & 6 & $\begin{array}{l}\text { I am satisfied with my social } \\
\text { life outside of class }\end{array}$ & 33.73 & 3.39 & 0.68 & .79 \\
\hline Financial support & 3 & $\begin{array}{l}\text { Financial aid is important for my } \\
\text { continuation at the university }\end{array}$ & 7.89 & 2.63 & 1.17 & .76 \\
\hline
\end{tabular}

The Likert response scale of SACQ ranges between 1 (Does not apply to me at all) to 9 (Applies very closely to me). The Likert response scale of SIQ ranges between 1 (Totally disagree) to 5 (Totally agree). For comparison, both SACQ and SIQ are illustrated on scale 1-5 in Table 1

component had an eigenvalue of 2.63 (corresponding to $18 \%$ of the explained variance), the third component had an eigenvalue of 2.00 (corresponding to 13\% of the explained variance) and the fourth component had an eigenvalue of 1.34 (corresponding to $9 \%$ of the explained variance). All items tapping the students' satisfaction with social life scale loaded on the first factor, the items tapping the study support scale loaded on the second factor, items tapping the financial support scale loaded on the third factor and finally the items tapping the perception of the faculty scale loaded on the fourth factor.

Secondly, in order to test the structure of the four components of the social integration questionnaire that was found in the exploratory factor analysis, confirmatory factor analysis (CFA) was used on another dataset, collected in the other four institutions $(n=429)$. The model showed a good fit to the observed data as suggested by the goodness-of-fitindices $\left(\chi^{2} / \mathrm{df}=2.10 ;\right.$ SRMR $=.06$, RMSEA $\left.=.10 ; \mathrm{CFI}=.94\right)$. The Cronbach's alpha were .69 for the perception of the faculty scale, .71 for the study support scale, .73 for the students' satisfaction with social life scale, and .67 for the financial support scale.

\section{Academic performance}

The academic performance of the participating students was assessed by taking into account the number of ECTS credits (a regular business track contains 60 ECTS in 1 year) obtained after 1 year of study as well as the student's grade point average after 1 year (GPA). In total, $91 \%$ of the ID-numbers could be linked with the academic performance data of the administrative systems of the five business schools. 


\section{Ethnicity}

Ethnic identity was measured by four open questions, namely mother's mother tongue, father's mother tongue, own mother tongue and official citizenship(s) (Rienties et al. 2011). As a result, in total 79 nationalities and 129 ethnic identities were present in the database.

In order to prevent a fragmented approach of comparing a limited number of students within each ethnic category, students were categorized according to the "degree of Westernness", which is inspired by the cultural classification system of Hofstede (2001) and the notion of cultural distance (Furnham and Alibhai 1985; Ward and Kennedy 1993). Ward and Kennedy (1993) found that psychological and sociocultural adjustment for international students was easier when they make a relatively small cross-cultural transition (e.g. from Germany to the Netherlands) rather than a large cross-cultural transition (e.g. from China to the Netherlands). Furnham and Alibhai (1985) refers to this notion as cultural distance, whereby international students with similar values will experience less stress when studying in a foreign country than students with different values.

We assumed that the more Western influences a student underwent, the easier it is for the student to adjust to the Dutch educational culture. Thus, in each of the four categories a distinction was made between Western (European Union, USA, Canada, Australia, New Zealand) versus non-Western cultures. Consequently, four groups (Dutch, Western, mixedWestern, non-Western) were distinguished. Domestic students can thus be compared to students that had a completely Western background (e.g. a German student with two German parents who speak German at home), a mixed-Western background (e.g. a German student with Turkish parents who were born and raised in Germany but speak Turkish at home), or a purely non-Western background (e.g. Chinese students with Chinese parents).

Data analysis

First, correlation analysis explored the relation between the SACQ components, the SIQ components and the students' grades and ECTS. Second, Analysis of Variance (ANOVA) explored differences between the four groups of students. Finally, regression-analyses were conducted in order to identify whether the students' demographic information, the SACQ and the SIQ components predict students' grades and the amount of achieved study-points (ECTS).

\section{Results}

Preliminary results

Table 2 shows the results for the correlation analysis and indicates that the four subscales of the SACQ have high significantly positive correlations, as was found in previous research (Baker and Siryk 1999; Beyers and Goossens 2002). Next, the social integration components are significantly positive correlated, except for the financial support scale that shows a significantly negative correlation with the perception of the faculty scale. Furthermore, there is a significantly positive correlation between the SACQ scales and the social integration scales, again except for financial support. Finally, the average grade after 1 year (GPA) is significantly positively correlated with academic adjustment, personalemotional adjustment, attachment and the perception of the faculty, while the average 


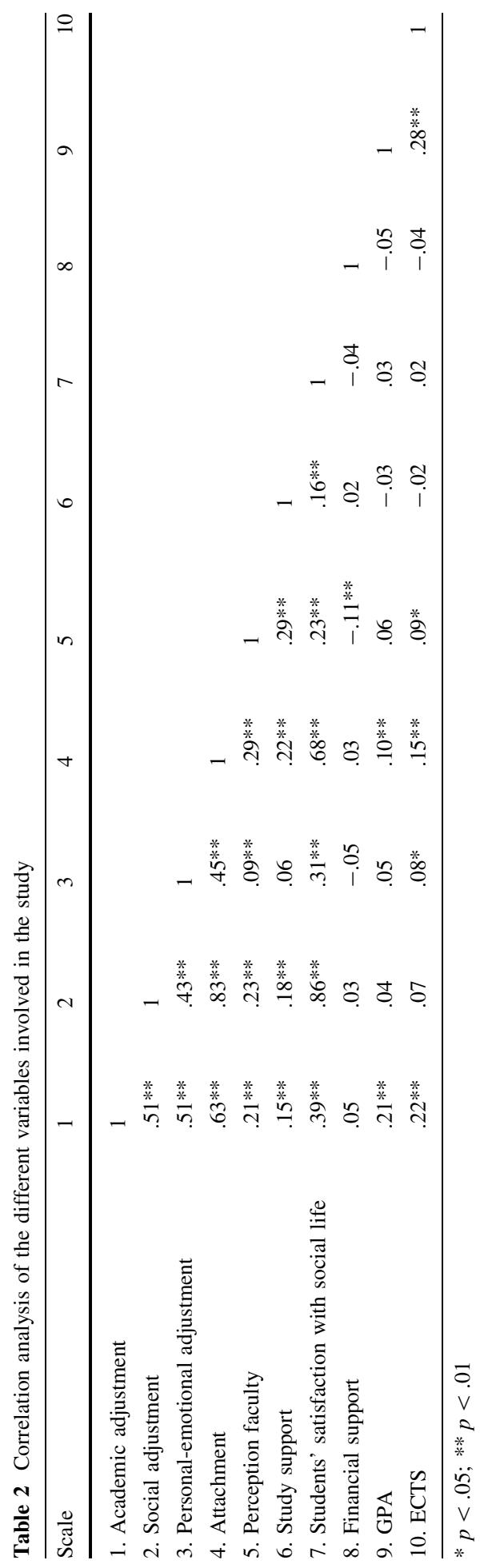


number of credits obtained after 1 year (ECTS) only correlates with academic adjustment and attachment. The students' GPA and ECTS do not correlate significantly with the newly added social integration scales.

ANOVA

In order to gain a more detailed perspective of the different (sub)groups of international students, Table 3 illustrates the academic and social integration of Dutch, Western, mixedWestern and non-Western students. In comparison to Dutch students, Western students score higher on all scales of academic integration with the exception of personal/emotional adjustment. In other words, Western students indicate to be well-adapted to the host institute, but their personal/emotional well-being is relatively lower than Dutch students. Western students attain a higher GPA and a higher number of ECTS than Mixed-Western, Dutch and non-Western students.

In comparison to Dutch and Western students, mixed-Western student score significantly higher on all dimensions of academic integration. Furthermore, mixed-Western students score highest on support by family and friends and social life. GPA and ECTS scores of mixed-Western students are similar to Dutch students but significantly lower than those of Western students. In other words, mixed-Western students seem to be welladapted to the academic and social requirements of higher education, which seems to contradict with research on mixed-Western or ethnic minority students in the Netherlands that showed a lower academic or social adjustment and/or study-performance (Meeuwisse et al. 2010; Severiens and Wolff 2008).

Table 3 Comparison of academic and social integration across four groups of students

\begin{tabular}{|c|c|c|c|c|c|c|c|c|c|}
\hline & \multicolumn{2}{|l|}{ Dutch } & \multicolumn{2}{|c|}{$\begin{array}{l}\text { Western (non } \\
\text { Dutch) }\end{array}$} & \multicolumn{2}{|c|}{$\begin{array}{l}\text { Mixed } \\
\text { Western }\end{array}$} & \multicolumn{2}{|c|}{ Non-Western } & \multirow[t]{2}{*}{ F value } \\
\hline & M & SD & M & SD & M & SD & M & SD & \\
\hline Academic adjustment & 141.57 & 20.03 & 144.15 & 20.13 & 150.07 & 22.96 & 144.04 & 22.81 & $3.503 * *$ \\
\hline Social adjustment & 123.46 & 17.19 & 126.08 & 20.08 & 130.52 & 16.92 & 113.25 & 22.88 & $13.539 * *$ \\
\hline $\begin{array}{l}\text { Personal/emotional } \\
\text { adjustment }\end{array}$ & 94.95 & 17.57 & 89.78 & 18.49 & 92.14 & 18.09 & 84.89 & 17.57 & $8.155^{* *}$ \\
\hline Attachment & 103.85 & 14.50 & 106.34 & 15.45 & 107.10 & 15.95 & 94.52 & 17.80 & $14.826 * *$ \\
\hline Perception of faculty & 10.96 & 2.04 & 11.80 & 2.14 & 10.99 & 2.07 & 10.91 & 1.97 & $12.892 * *$ \\
\hline Study support & 12.24 & 2.19 & 12.04 & 2.41 & 12.31 & 2.69 & 11.55 & 2.47 & $2.234^{\dagger}$ \\
\hline $\begin{array}{l}\text { Student's satisfaction } \\
\text { with social life }\end{array}$ & 33.43 & 6.06 & 33.93 & 6.85 & 36.59 & 5.72 & 30.74 & 7.71 & $10.201^{* *}$ \\
\hline Financial support & 8.60 & 3.38 & 7.24 & 3.42 & 9.35 & 3.76 & 7.51 & 3.01 & $15.324 * *$ \\
\hline GPA & 6.63 & 0.97 & 7.01 & 0.94 & 6.82 & 0.71 & 6.66 & 0.64 & $10.905^{* * *}$ \\
\hline ECTS & 52.59 & 11.18 & 55.65 & 9.12 & 51.62 & 12.35 & 49.69 & 13.89 & $10.598 * *$ \\
\hline
\end{tabular}

ANOVA F-Test for Dutch students $(n=288)$, Western students $(n=479)$, mixed-Western students $(\mathrm{n}=85)$ and non-Western students $(\mathrm{n}=90)$

** Coefficient is significant at the 0.01 level (2-tailed)

* Coefficient is significant at the 0.05 level (2-tailed)

$\dagger$ Coefficient is significant at the 0.10 level (2-tailed) 
Finally, non-Western students score significantly lower on all elements of academic integration with the exception of academic adjustment. In particular, non-Western students have lower scores for social, personal and emotional adjustment, which indicates that adaptation to the ('Western') way of life at university is more difficult for non-Western students. Furthermore, non-Western students score significantly lower on the added four social integration scales, which indicated that the social support structures of family and friends for non-Western students is more problematic than for other students. This finding is in line with Russell et al. (2010), who find that non-Western students are likely to cope with more issues of adaptation. Finally, non-Western students score significantly lower on both GPA and ECTS compared to Western students. This difference disappears when we compare non-Western with Dutch or mixed-Western students. In other words, despite lower scores on academic and social integration, after 1 year of study non-Western students perform similar to the domestic and the mixed-Western students.

\section{Regression analysis}

The hierarchical regression analysis of the academic integration components on ECTS and GPA, controlling for the background variables gender and ethnicity, showed that academic adjustment $(\beta=.25 ; p<.001)$ predicted students' ECTS significantly positive, while social adjustment predicted students' ECTS significantly negatively $(\beta=-.17 ; p<.01)$. GPA was only significantly predicted by academic adjustment $(\beta=.27 ; p<.001)$. The regression analysis of the social integration components on ECTS and GPA, controlling for the background variables gender and ethnicity, showed that none of the international students' social integration components predict students' ECTS or GPA significantly.

In addition, to detect differences in the relationship between academic and social adjustment on the one hand and students' ECTS and GPA on the other hand, four similar regression analyses were performed. For each ethnicity group (Dutch, Western, non-Dutch, Mixed-Western and Non-Western), significant relations with the academic integration components as independent variables are indicated with positive or negative signs in Table 4. Again, the data were controlled for gender. It was found that academic integration predicts students' ECTS significantly for domestic students $\left(\beta=.23, p<.01 ; \Delta \mathrm{R}^{2}=.07\right.$, $p<.01)$, Western/non-Dutch students $\left(\beta=.23, p<.01 ; \Delta \mathrm{R}^{2}=.08, p<.001\right)$ and mixed Western students $\left(\beta=.42, p<.05 ; \Delta \mathrm{R}^{2}=.09\right.$, ns). Furthermore, social adjustment predicts ECTS significantly negative for Western/non-Dutch students $(\beta=-.19$, $\left.p<.05 ; \Delta \mathrm{R}^{2}=.08, p<.001\right)$. The academic integration components do not significantly predict ECTS for non-Western students.

Finally, academic integration predicts students' GPA significantly positive for all distinguished groups (Dutch: $\beta=.23, p<.01 ; \Delta \mathrm{R}^{2}=.06, p<.01$-Western, non-Dutch:

Table 4 Regression analysis of academic and social adjustment on ECTS and GPA

\begin{tabular}{|c|c|c|c|c|c|c|c|c|}
\hline & \multicolumn{4}{|l|}{ ECTS } & \multicolumn{4}{|l|}{ GPA } \\
\hline & Dutch & Western & $\begin{array}{l}\text { Mixed- } \\
\text { Western }\end{array}$ & $\begin{array}{l}\text { Non- } \\
\text { Western }\end{array}$ & Dutch & Western & $\begin{array}{l}\text { Mixed- } \\
\text { Western }\end{array}$ & $\begin{array}{l}\text { Non- } \\
\text { Western }\end{array}$ \\
\hline $\begin{array}{l}\text { Academic } \\
\text { Adjustment }\end{array}$ & + & + & + & & + & + & + & + \\
\hline $\begin{array}{l}\text { Social } \\
\text { Adjustment }\end{array}$ & & - & - & & & & & - \\
\hline
\end{tabular}


$\beta=.25, p<.001 ; \Delta \mathrm{R}^{2}=.04, p<.01-$ Mixed Western: $\beta=.45 ; p<.05 ; \Delta \mathrm{R}^{2}=.12$, ns-non-Western: $\left.\beta=.71 ; p<.001 ; \Delta \mathrm{R}^{2}=.18, p<.01\right)$, but social adjustment only predicts non-Western students' GPA significantly negatively $(\beta=-.53, p<.05$; $\left.\Delta \mathrm{R}^{2}=.18, p<.01\right)$.

\section{Conclusion and discussion}

In this study, we investigated how academic and social integration relates to academic performance for 670 international students and 288 Dutch students at five business schools in the Netherlands. A common assumption among educators is that academic and social integration of international students (the extent to which students adapt to the academic and social way of life) is not yet well-articulated in the policies and practices of Western institutes for higher education. In order to gain a perspective on this (perceived) lack of adjustment, this study identifies the underlying factors for students' successful or failing integration and academic performance, as suggested by Christie et al. (2004).

A main significant finding is that academic performance is affected positively by academic integration. Correlation analyses indicate significantly that academic performance after 1 year is positively correlated with three of the four academic integration scales of Baker and Siryk (1999): academic adjustment, personal-emotional adjustment and attachment. For measuring the degree of social integration, we added 15 items to the SACQ model in order to include the degree of diversity in the situation of international student. Only the perception of the faculty by people in the social network of the student is positively correlated with ECTS. This indicates that a perceived good reputation of an institute has a positive influence on the students' persistence.

A second major finding is that the successfulness of academic and social integration is partly related to the distance in East-West social conventions among international students. In general, Western students score better than Dutch students on academic integration and study-performance. Western students who study abroad are in general 1 or 2 years older than their domestic peer students (Russell et al. 2010) and their reason to study abroad is a more conscious choice. As a result, Western students' motivation and learning attitudes are significantly more adjusted to the demand of higher education than those of domestic students (Tempelaar et al. 2006).

Mixed-Western students have significantly higher academic and social integration scores in comparison to domestic students. This is a positive and optimistic finding for all educators and researchers who are involved in increasing the success of internationalisation in higher education (Asmar 2005; Morrison et al. 2005; Van der Wende 2003; Zhou et al. 2008). A possible explanation why mixed-Western students perform equally or better than domestic students may be due to job-prospects and subsequent reputation following business education, which may have a positive impact on motivation and support given by their social network. While previous research on teacher education showed lower success rates of completion among ethnic minority students (Meeuwisse et al. 2010; Severiens and Wolff 2008), in business education no difference in completion and success is found.

Non-Western students have significantly lower scores on academic and social integration in comparison to other students, with the exception of academic adjustment. In particular, non-Western students have more adjustment issues, which leads to lower personal/emotional well-being. By adding criteria for social integration, we could detect that non-Western students receive less support from family and friends, be it in the form of encouragement, emotional or financial support. In other words, non-Western students face 
more obstacles before they can actually integrate in academic life compared to the other student groups. Despite these impediments, non-Western students perform equally well after 1 year of study as domestic students, which is primarily due to the successful academic adjustment of non-Western students.

As a third major finding, we find a compensatory relationship between academic and social adjustment and study-performance. Regression analyses indicate that academic success of students is primarily determined by academic integration, in particular by the degree of academic adjustment. However, social adjustment influenced the students' success in terms of ECTS negatively, which is in contrast to the theoretical model of Tinto. However, previous research has found similar contradicting findings (Mannan 2007; Zepke and Leach 2005). For example, a strong negative relationship between academic and social integration was found in the study of Mannan (2007), which he calls the "compensatory relationship" between academic and social integration. This may be explained as follows: students who are extensively involved in extracurricular activities may devote less time on academic activities, which eventually leads to lower study-performance. In contrast, students who are less involved with social and extracurricular activities may compensate the lower social integration with more academic interests and integration. In other words, students who try to maximise their efforts to integrate academically have better learning outcomes, while this is not necessarily the case for students who maximize their efforts to integrate socially. In order to clarify the influence of social adjustment and the other social integration components on students' success, more research should be undertaken.

Finally, when controlling for the results by ethnic background, academic adjustment predicts grade point average for all four groups of students. Furthermore, academic adjustment predicts study-performance in terms of obtained credits after 1 year for each of the three "Western" groups but not for non-Western students. Social adjustment leads to negative study-performance in terms of obtained credits after 1 year for (mixed) Western students but not in terms of average grades. When (mixed) western international students have an extensive and busy social calendar, these students are more selective in deciding for which exams they make an active effort. Non-Western students who are more socially adjusted and actively participate in student life are less likely to obtain good average grades. In sum, despite substantial differences in the degree of academic and social integration between the four groups of students, academic performance after 1 year of study is primarily determined by the degree to which students are academically adjusted, and not by ethnicity. This is an important finding, in particular given that most research on crosscultural research (Ward and Kennedy 1993; Ward et al. 1998; Ward and Rana-Deuba 1999) and adaptation of international students to higher education (Zhou et al. 2008) does not explicitly take the concept of academic adjustment into consideration.

\section{Constraints and limitations}

A first limitation of this research is that we used self-reported scores of students on academic and social integration. Besides the known issues with using self-reported scores, groups or persons who are "at risk" might not have returned the questionnaire or would have filled in the questionnaire in a socially desirable manner. However, by distributing the validated questionnaires in class on paper in five business schools, we were able to compare academic and social integration among a large sample of first-year students, which strengthens our findings in comparison to studies using a single-institute analysis or a comparison among various disciplines of study (Mannan 2007; Severiens and Wolff 
2008). Factor analyses and subsequent reliability of constructs analyses indicate an adequate fit with the questionnaire on social integration.

A second limitation of this research is that we clustered the 79 nationalities and 129 ethnic identities into four groups. By aggregating (in particular) non-Western citizens from various countries into one category may oversimplify specific cultural adjustment processes across different countries, continents and cultures. One possible explanation for the lack of fit of our model for academic performance of non-Western students in terms of obtained credit points is that adding up the 58 different ethnicities of international students from Asia, Africa or South America into one common category of non-Western students might have levelled away the more subtle differences. The fact that we did not control for differences in motivation, educational background, prior experience and learning attitudes for (non-Western) students might explain the lack of fit for our model. In the near future, we hope to extend our sample of non-Western students in order to be able to cluster non-Western students into statistically meaningful sub-groups. In addition, in-depth focus group discussions will be held in the near future in order to obtain a finer grain-sized understanding of the underlying dynamics of academic and social integration.

\section{Practical implications}

Most institutes for higher education provide several introduction activities and social support structures for new students in order to facilitate their academic and social integration. Based upon our findings, rather than focussing purely on social integration we encourage higher educational institutes to specifically address measures that can enhance academic adjustment of (international) students. This can for example be done by providing more information about the educational culture of the institute before international students move to the host university. Even better would be to allow international students to experience the educational learning approach of the host institute before starting with their bachelor program. In particular, by focusing on the expected domain-specific knowledge, language proficiency, skills and attitudes before the start of the academic program, institutes can actively enhance the awareness of international students of the demands of higher education. Research at one of the participating business schools (Rienties et al. 2006; Tempelaar et al. 2011) has found that providing online summer courses for international students in economics or mathematics not only enhances their domainspecific knowledge but also provides a social network for international students at the institute itself. Finally, institutes can provide buddies for international students to facilitate the transition in academic and social life, whereby a mix of social activities and study support is recommended.

Acknowledgments This research has been financed by SURF Foundation as part of the NAP acculturatie project (http://www.acculturation.nl/). We found like to thank the following people who helped with the data collection at the five business schools (in alphabetical order): Jan Brouwer, Peter Dekker, Brechtine Detmar, Sylvia Hermans, Ria Jacobi, Paul Jacobs, Bert Kamphuis, Ilja Kogan, Albert Lamberix, Mascha Lommertzen, Wim Swaan, Marleen van der Laan.

Open Access This article is distributed under the terms of the Creative Commons Attribution Noncommercial License which permits any noncommercial use, distribution, and reproduction in any medium, provided the original author(s) and source are credited. 


\section{References}

Asmar, C. (2005). Internationalising students: Reassessing diasporic and local student difference. Studies in Higher Education, 30(3), 291-309.

Attewell, P., Lavin, D., Domina, T., \& Levey, T. (2006). New evidence on college remediation. The Journal of Higher Education, 77(5), 886-924.

Baker, R. W., \& Siryk, B. (1999). SACQ student adaptation to college questionnaire (2nd ed.). Los Angeles: Western Psychological Services.

Barrie, S. C. (2007). A conceptual framework for the teaching and learning of generic graduate attributes. Studies in Higher Education, 32(4), 439-458.

Berry, J. W. (1999). Intercultural relations in plural societies. Canadian Psychology, 40(1), 12-21.

Beyers, W., \& Goossens, L. (2002). Concurrent and predictive validity of the student adaptation to college questionnaire in a sample of European freshman students. Educational and Psychological Measurement, 62(3), 527-538.

Bochner, S., McLeod, B. M., \& Lin, A. (1977). Friendship patterns of overseas students: A functional model. International Journal of Psychology, 12(4), 277-294.

Bok, D. C. (2003). Universities in the marketplace: The commercialization of higher education. Princeton: Princeton University Press.

Christie, H., Munro, M., \& Fisher, T. (2004). Leaving university early: Exploring the differences between continuing and non-continuing students. Studies in Higher Education, 29, 617-636.

Cokley, K., Bernard, N., Cunningham, D., \& Motoike, J. (2001). A psychometric investigation of the academic motivation scale using a United States sample. Measurement and Evaluation in Counseling and Development, 34(2), 109-119.

Dutch Ministery of Education. (2010). Kennis in Kaart 2009 (Mapping Knowledge of Education 2009). from http://www.rijksoverheid.nl/bestanden/documenten-en-publicaties/publicaties-pb51/kennis-in-kaart-2009/ kennis-in-kaart-2009-pdf-2-mb.pdf.

Eringa, K., \& Huei-Ling, Y. (2009). Chinese students' perceptions of the intercultural competence of their tutors in PBL. In D. Gijbels \& P. Daly (Eds.), Real learning opportunities at business school and beyond (Vol. 2, pp. 17-37). Netherlands: Springer.

Furnham, A., \& Alibhai, N. (1985). The friendship networks of foreign students: A replication and extension of the functional model. International Journal of Psychology, 20(6), 709.

Gloria, A. M., Castellanos, J., Lopez, A. G., \& Rosales, R. (2005). An examination of academic nonpersistence decisions of Latino undergraduates. Hispanic Journal of Behavioral Sciences, 27(2), 202-223.

Healey, N. (2008). Is higher education 'internationalising'? Higher Education, 55(3), 333-355.

Hofstede, G. (2001). Culture's consequences: Comparing values, behaviours, institutions, and organizations across nations. Thousand Oaks: Sage Publications.

Jochems, W., Snippe, J., Smid, H. J., \& Verweij, A. (1996). The academic progress of foreign students: Study achievement and study behaviour. Higher Education, 31(3), 325-340.

Mannan, M. (2007). Student attrition and academic and social integration: Application of Tinto's model at the University of Papua New Guinea. Higher Education, 53(2), 147-165.

Meeuwisse, M., Severiens, S. E., \& Born, M. P. (2010). Reasons for withdrawal from higher vocational education. A comparison of ethnic minority and majority non-completers. Studies in Higher Education, 35(1), 93-111.

Morrison, J., Merrick, B., Higgs, S., \& Le Métais, J. (2005). Researching the performance of international students in the UK. Studies in Higher Education, 30(3), 327-337.

OECD. (2009). Education at a glance 2009. from http://www.oecd.org/dataoecd/41/25/43636332.pdf.

Ozga, J., \& Sukhnandan, L. (1998). Undergraduate non-completion: Developing an explanatory model. Higher Education Quarterly, 52(3), 316-333.

Phinney, J. S. (1990). Ethnic identity in adolescents and adults: Review of research. Psychological Bulletin, 108(3), 499-514.

Rienties, B., Grohnert, T., Kommers, P., Niemantsverdriet, S., \& Nijhuis, J. (2011). Academic and social integration of international and local students at five business schools, a cross-institutional comparison. In P. Van den Bossche, W. H. Gijselaers \& R. G. Milter (Eds.), Building learning experiences in a changing world (Vol. 3, pp. 121-137). Netherlands: Springer.

Rienties, B., Tempelaar, D. T., Waterval, D., Rehm, M., \& Gijselaers, W. H. (2006). Remedial online teaching on a summer course. Industry and Higher Education, 20(5), 327-336.

Russell, J., Rosenthal, D., \& Thomson, G. (2010). The international student experience: Three styles of adaptation. Higher Education, 60(2), 235-249. 
Sam, D. L., \& Berry, J. W. (2006). The Cambridge handbook of acculturation psychology. Cambridge: Cambridge University Press.

Severiens, S., \& Wolff, R. (2008). A comparison of ethnic minority and majority students: Social and academic integration, and quality of learning. Studies in Higher Education, 33, 253-266.

Tempelaar, D. T., Rienties, B., Giesbers, B., \& Schim van der Loeff, S. (2011). Effectiveness of a voluntary postsecondary remediation program in mathematics. In P. Van den Bossche, W. H. Gijselaers, \& R. G. Milter (Eds.), Advances in business education and training (Vol. 4). Dordrecht: Springer.

Tempelaar, D. T., Rienties, B., \& Gijselaers, W. H. (2006). Internationalisering: en de Nederlandse student? Onderzoek van Onderwijs, 35(3), 40-45.

Thomas, L. (2002). Student retention in higher education: The role of institutional habitus. Journal of Education Policy, 17(4), 423-442.

Tinto, V. (1975). Dropout from higher education: A theoretical synthesis of recent research. Review of Educational Research, 45(1), 89-125.

Tinto, V. (1998). Colleges as communities: Taking research on student persistence seriously. The Review of Higher Education, 21(2), 167-177.

Van der Wende, M. C. (2003). Globalisation and access to higher education. Journal of Studies in International Education, 7(2), 193-206.

Ward, C., \& Kennedy, A. (1993). Where's the "culture" in cross-cultural transition? Journal of CrossCultural Psychology, 24(2), 221-249.

Ward, C., Leong, C. -H., \& Low, M. (2004). Personality and sojourner adjustment. Journal of CrossCultural Psychology, 35(2), 137-151.

Ward, C., Okura, Y., Kennedy, A., \& Kojima, T. (1998). The U-Curve on trial: A longitudinal study of psychological and sociocultural adjustment during Cross-Cultural transition. International Journal of Intercultural Relations, 22(3), 277-291.

Ward, C., \& Rana-Deuba, A. (1999). Acculturation and adaptation revisited. Journal of Cross-Cultural Psychology, 30(4), 422-442.

Wilcox, P., Winn, S., \& Fyvie-Gauld, M. (2005). It was nothing to do with the university, it was just the people: The role of social support in the first-year experience of higher education. Studies in Higher Education, 30(6), 707-722.

Yazedjian, A., \& Toews, M. (2006). Predictors of college adjustment among Hispanic students. Journal of the First-Year Experience \& Students in Transition, 18(2), 9-29.

Zepke, N., \& Leach, L. (2005). Integration and adaptation. Active Learning in Higher Education, 6(1), 46-59.

Zhou, Y., Jindal-Snape, D., Topping, K., \& Todman, J. (2008). Theoretical models of culture shock and adaptation in international students in higher education. Studies in Higher Education, 33(1), 63-75. 